\title{
Measurement of Membrane Characteristics Using the Phenomenological Equation and the Overall Mass Transport Equation in Ion-Exchange Membrane Electrodialysis of Saline Water
}

\author{
Yoshinobu Tanaka \\ IEM Research, 1-46-3 Kamiya, Ushiku-shi, Ibaraki 300-1216, Japan \\ Correspondence should be addressed to Yoshinobu Tanaka, fwis1202@mb.infoweb.ne.jp
}

Received 6 November 2011; Accepted 18 January 2012

Academic Editor: Seung Hyeon Moon

Copyright (C) 2012 Yoshinobu Tanaka. This is an open access article distributed under the Creative Commons Attribution License, which permits unrestricted use, distribution, and reproduction in any medium, provided the original work is properly cited.

\begin{abstract}
The overall membrane pair characteristics included in the overall mass transport equation are understandable using the phenomenological equations expressed in the irreversible thermodynamics. In this investigation, the overall membrane pair characteristics (overall transport number $\lambda$, overall solute permeability $\mu$, overall electro-osmotic permeability $\phi$ and overall hydraulic permeability $\rho$ ) were measured by seawater electrodialysis changing current density, temperature and salt concentration, and it was found that $\mu$ occasionally takes minus value. For understanding the above phenomenon, new concept of the overall concentration reflection coefficient $\sigma^{*}$ is introduced from the phenomenological equation. This is the aim of this investigation. $\sigma^{*}$ is defined for describing the permselectivity between solutes and water molecules in the electrodialysis system just after an electric current interruption. $\sigma^{*}$ is expressed by the function of $\mu$ and $\rho$. $\sigma^{*}$ is generally larger than 1 and $\mu$ is positive, but occasionally $\sigma^{*}$ becomes less than 1 and $\mu$ becomes negative. Negative $\mu$ means that ions are transferred with water molecules (solvent) from desalting cells toward concentrating cells just after an electric current interruption, indicating up-hill transport or coupled transport between water molecules and solutes.
\end{abstract}

\section{Introduction}

Mass transport across the membrane must be discussed fundamentally on the basis of the thermodynamics because the thermodynamics describes the rule of energy changes inevitably generating in the mass transport. However, the classical thermodynamics discusses only reversible phenomena and it does not treat transport rate. The irreversible thermodynamics came to succeed in discussing the transport rate by introducing the concept of "time" in its system [1-4]. Basic theory of the irreversible thermodynamics is established on the assumption of "microscopic irreversibility" [5-7]. This assumption holds more strictly in the circumstance being more close to equilibrium states. The actual electrodialysis process is not formed in the equilibrium states, so that the irreversible thermodynamics is assumed to exhibit only approximated meaning in the electrodialysis system. However, the irreversible thermodynamics is considered to be applicable in the circumstances being apart to some extent from equilibrium states $[8,9]$. The irreversible thermodynamics is the fundamental rule of mass transport and it is expressed by the functions including phenomenological coefficients. On the other hand, the performance of an electrodialyzer is expressed by the functions including parameters such as electrodialysis conditions and process specifications. These parameters cannot be discussed directly based on the irreversible thermodynamics. In the previous investigation, the overall mass transport equation was related to the irreversible thermodynamics and developed for analyzing the performance of an electrodialyzer [10]. It was successfully employed in the computer simulation of an electrodialysis process [11-13]. The overall mass transport equation includes the parameters such as the overall transport number $\lambda$, the overall solute permeability 
$\mu$, the overall electro-osmotic permeability $\phi$, and the overall hydraulic permeability $\rho$. Among these parameters, $\mu$ is very small values and further in some cases, $\mu$ was found to take negative values. In such cases, $\mu$ has been conventionally neglected by setting $\mu=0$. The aim of this investigation is to establish reasonable explanation of the negative $\mu$. For understanding this phenomenon, the concept of the overall concentration reflection coefficient $\sigma^{*}[10]$ must be supplied.

\section{Theoretical}

2.1. Phenomenological Equation and Overall Mass Transport Equation. When two kinds of ions are transported with solvent in a solution, their fluxes influence each other, because the fluxes and driving forces are not independent and coupled together. The interactions are presented in the irreversible thermodynamics. Kedem and Katchalsky introduced the following phenomenological equation expressing the electric current $I$, volume flow of a solution $J$ and mass flux of component $i ; J_{i}$ in a membrane system [14],

$$
\begin{aligned}
& I=L_{E} \Delta \psi+L_{E P} \Delta P+\sum_{i} L_{E i} \Delta \mu_{i}, \\
& J=L_{P E} \Delta \psi+L_{P} \Delta P+\sum_{i} L_{P i} \Delta \mu_{i}, \\
& J_{i}=L_{i E} \Delta \psi+L_{i P} \Delta P+\sum_{k} L_{i k} \Delta \mu_{k}
\end{aligned}
$$

$\Delta \psi$ is a potential difference, $\Delta P$ is a pressure difference, and $\Delta \mu_{i}$ is a chemical potential difference across the membrane. House [15] discussed an electrokinetic phenomenon based on the approaches of Kedem and Katchalsky [14]. Referring to this suggestion, Schultz discussed the principle of salt and solvent (water) transport in a two-cell electrodialysis system (cell I and cell II) incorporated with a cationexchange membrane and introduced the following equations expressing the flux of solutes $J_{S, K}$ and a solution $J_{V, K}$ across the membrane [16],

$$
\begin{gathered}
J_{S, K}=t_{K} \frac{i}{F}+\left\{\omega_{K}-L_{P, K} \sigma_{K}\left(1-\sigma_{K}\right) C_{S}^{*}\right\} R T \Delta C_{S}, \\
J_{V, K}=\beta_{K} i-\sigma_{K} L_{P, K} R T \Delta C_{S}
\end{gathered}
$$

in which $t$ is the transport number, $\omega$ is the solute permeability, $\beta$ is the electro-osmotic permeability, $L_{P}$ is the hydraulic permeability, $\sigma_{K}$ is the reflection coefficient of the cation-exchange membrane, and these phenomenological coefficients are membrane characteristics. $R$ is the gas constant, $F$ is the Faraday constant, and $T$ is the absolute temperature. $\Delta C_{S}=\left(C_{S}{ }^{\mathrm{II}}-C_{S}{ }^{\mathrm{I}}\right)$ is salt concentration difference between cell II and cell I. $C_{S}{ }^{*}$ is the logarithmic mean concentration across the membrane defined by

$$
C_{S}^{*}=\frac{\Delta C_{S}}{\ln \left(C_{S}^{\mathrm{II}} / C_{S}^{\mathrm{I}}\right)} .
$$

The principle of separating salt from water is introduced based on the theory mentioned above using a three-cell

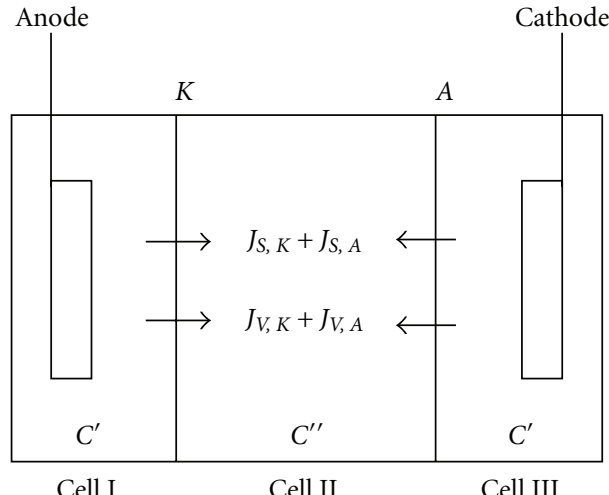

K: Cation-exchange membrane $A$ : Anion-exchange membrane

Figure 1: Three-cell electrodialysis system.

electrodialysis system (Figure 1). The system consists of a central cell (cell II) and electrode cells (cell I and cell III) placed on both outsides of cell II. A cation-exchange membrane $(K)$ is placed between cell I and cell II, and an anion-exchange membrane $(A)$ is placed between cell II and cell III. Supplying a salt solution into cell I and cell III, constant current density $i$ is applied and a salt solution being collected in cell II is taken out from the system until the salt concentration in cell II reaches steady constant. Salt accumulation $J_{S, K}+J_{S, A}$ and solution accumulation $J_{V, K}+$ $J_{V, A}$ in cell II in the steady state are given by the following equation introduced from (2) [10]:

$$
\begin{aligned}
J_{S, K}+J_{S, A}= & \left(t_{K}+t_{A}-1\right) \frac{i}{F}-R T \\
& \times\left[\left(\omega_{K}+\omega_{A}\right)-\left\{L_{P, K} \sigma_{K}\left(1-\sigma_{K}\right)\right.\right. \\
& \left.\left.\quad+L_{P, A} \sigma_{A}\left(1-\sigma_{A}\right)\right\} C_{S}^{*}\right] \Delta C, \\
J_{V, K}+J_{V, A}= & \left(\beta_{K}+\beta_{A}\right) i+R T\left(\sigma_{K} L_{P, K}+\sigma_{A} L_{P, A}\right) \Delta C .
\end{aligned}
$$

Here, we put $\Delta C=C^{\prime \prime}-C^{\prime}=\Delta C_{S}$. $t_{K}$ and $t_{A}$ are transport number of counter ions of a cation- and an anionexchange membrane respectively. Subscripts $K$ and $A$ denote a cation- and an anion-exchange membrane. Superscripts and " denote desalting sides (cells I and III) and a concentrating side (cell II), respectively. $C_{S}^{*}$ is logarithmic mean concentration defined by (3).

The overall mass transport equation was developed from electrodialysis experiments as described in Section 3 experiment. Namely, a strong electrolyte solution is supplied to an electrodialyzer illustrated in Figure 2 keeping the linear solution velocities in desalting cells to be constant. Passing a constant electric current $i\left(\mathrm{~A} / \mathrm{cm}^{2}\right)$ through electrodes, concentrate is extracted from concentrating cells. After the electrolyte concentration reaches constant $\left(C^{\prime \prime}\right)$, salt concentration in desalting cells $C^{\prime}$ (equiv. $/ \mathrm{cm}^{3}$ ), ion flux $J_{S}$ (equiv. $\left./ \mathrm{cm}^{2} \mathrm{~s}\right)$ and volume flux $J_{V}\left(\mathrm{~cm}^{3} / \mathrm{cm}^{2} \mathrm{~s}\right)$ transported across a membrane pair are measured. Plotting $J_{S} / i$ and $J_{V} / i$ against $\left(C^{\prime \prime}-C^{\prime}\right) / i=\Delta C / i$ creates linear lines as exemplified 


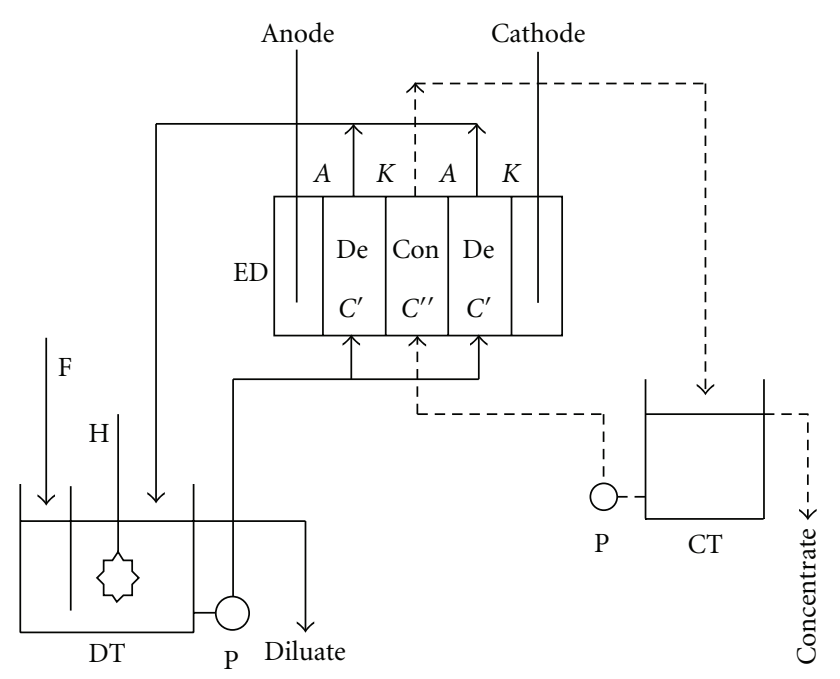

ED: Electrodialyzer $K$ : Cation-exchange membrane $A$ : Anion-exchange membrane De: Desalting cell Con: Concentrating cell
DT: Diluate tank CT: Concentrate tank F: Feeding solution P: Pump $\mathrm{H}$ : Heater

FIGURE 2: Electrodialysis process.

in Figures 3 and 4. These lines are expressed by the following overall mass transport equation [10]:

$$
\begin{gathered}
J_{S}=C^{\prime \prime} J_{V}=\lambda i-\mu\left(C^{\prime \prime}-C^{\prime}\right)=\lambda i-\mu \Delta C, \\
J_{V}=\phi i+\rho\left(C^{\prime \prime}-C^{\prime}\right)=\phi i+\rho \Delta C,
\end{gathered}
$$

in which $\lambda\left(\mathrm{eqC}^{-1}\right)$ is the overall transport number, $\mu\left(\mathrm{cm} \mathrm{s}^{-1}\right)$ is the overall solute permeability, $\phi\left(\mathrm{cm}^{3} \mathrm{C}^{-1}\right)$ is the overall electro-osmotic permeability, and $\rho\left(\mathrm{cm}^{4} \mathrm{eq}^{-1} \mathrm{~s}^{-1}\right)$ is the overall hydraulic permeability. These parameters are termed the overall membrane pair characteristics and they are measured easily from the intercepts and gradients of the linear lines. The term "overall" means that the coefficients express the contributions of a cation- and an anion-exchange membrane. It means also that the coefficients express the contributions of many types of ions dissolving in a strong electrolyte solution. Terms $\lambda i$ and $\mu \Delta C$ in (5) stand for migration and diffusion of ions. Terms $\phi i$ and $\rho \Delta C$ in (6) correspond to electro-osmosis and hydraulic osmosis of a solution. Osmosis refers to the movement of solvent in the original definition. However, the osmosis referred in (6) consists of the osmotic flow of solvent and of the volume flow associated with solutes.

The overall mass transport equation does not hold in the equilibrium state because it was developed from saline water electrodialysis experiments. It describes the mass transport in the nonequilibrium state. It is conceptually simple and available for discussing electrodialysis phenomena without contradictions.

In the electrodialysis experiments, the solutions supplied to desalting cells are mixed vigorously by spacers integrated. Thus, the boundary layer effects on the membrane surfaces

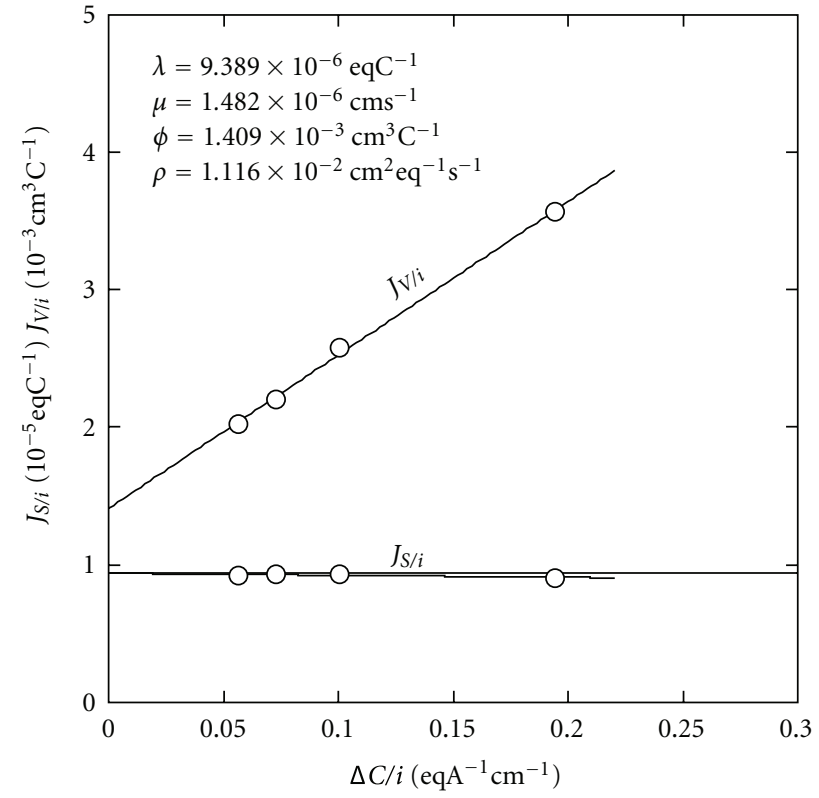

Figure 3: $J_{S} / i$ versus $\Delta C / i$ plot and $J_{V} / i$ versus $\Delta C / i$ plot. Selemion $\mathrm{CMR} / \mathrm{ASR} 25^{\circ} \mathrm{C}$.

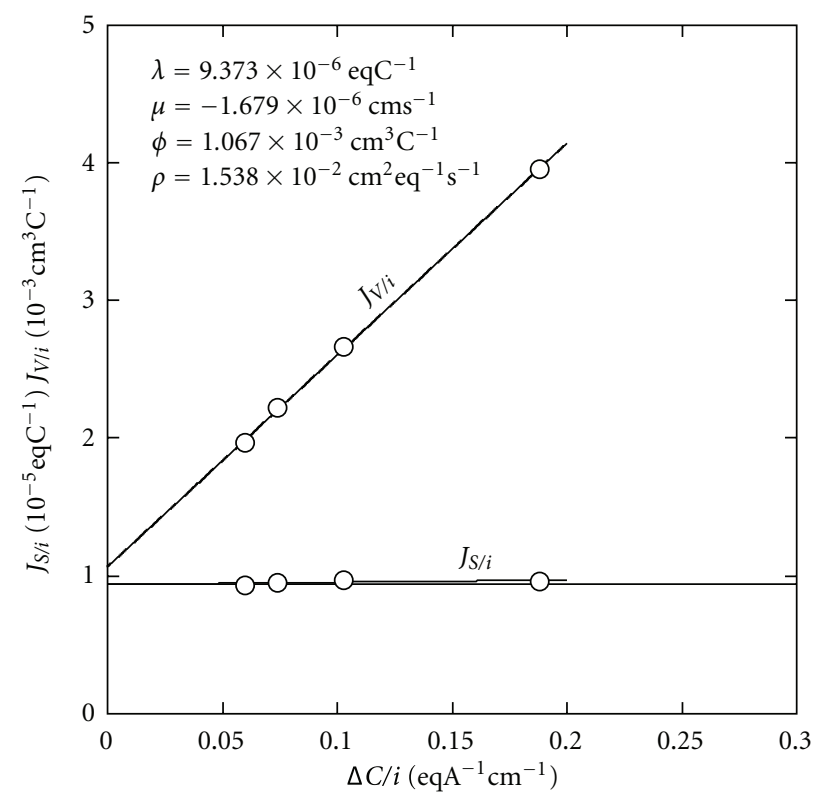

FIGURE 4: $J_{S} / i$ versus $\Delta C / i$ plot and $J_{V} / i$ versus $\Delta C / i$ plot. Neosepta $\mathrm{CIM} / \mathrm{ACS} 335^{\circ} \mathrm{C}$.

are assumed to be negligible. The influence of concentration polarization on the overall membrane pair characteristics were discussed in the previous investigation [10] and concluded that the membrane pair characteristics are not influenced by the concentration polarization.

\subsection{Overall Membrane Pair Characteristics and Phenomeno- logical Coefficients. The overall mass transport equation ((5)}


and (6)) is substantially identical to the phenomenological equation expressed in irreversible thermodynamics (4):

$$
\begin{gathered}
J_{S}=J_{S, K}+J_{S, A}, \\
J_{V}=J_{V, K}+J_{V, A} .
\end{gathered}
$$

From (7), the overall membrane pair characteristics $\lambda$, $\mu, \phi$ and $\rho$ are presented by the functions of the membrane characteristics defined in the phenomenological equation as follows:

$$
\begin{aligned}
\lambda= & \frac{t_{K}+t_{A}-1}{F}=\left(\frac{J_{S}}{i}\right)_{\Delta C=0} \\
\mu= & R T\left[\left(\omega_{K}+\omega_{A}\right)\right. \\
& \left.\quad-\left\{L_{P, K} \sigma_{K}\left(1-\sigma_{K}\right)+L_{P, A} \sigma_{A}\left(1-\sigma_{A}\right)\right\} C_{S}^{*}\right] \\
= & R T\left[\left(\omega_{K}+\omega_{A}\right)-\sigma(1-\sigma)\left(L_{P, K}+L_{P, A}\right) C_{S}^{*}\right] \\
= & \left(\frac{J_{S}}{\Delta C}\right)_{i=0}, \\
\phi & =\beta_{K}+\beta_{A}=\left(\frac{J_{V}}{i}\right)_{\Delta C=0}, \\
\rho & =R T\left(\sigma_{K} L_{P, K}+\sigma_{A} L_{P, A}\right), \\
& =R T \sigma\left(L_{P, K}+L_{P, A}\right)=\left(\frac{J_{V}}{\Delta C}\right)_{i=0} .
\end{aligned}
$$

Here, $\sigma_{K}$ and $\sigma_{A}$ are reflection coefficients of a cation- and an anion-exchange membrane respectively ((18) and (19)). $\sigma$ expresses the contributions of a cation- and an anionexchange membrane, so it is termed the overall reflection coefficient (Equation (20)) and it is introduced as follows. From (9):

$$
\sigma(1-\sigma)=\frac{L_{P, K} \sigma_{K}\left(1-\sigma_{K}\right)+L_{P, A} \sigma_{A}\left(1-\sigma_{A}\right)}{L_{P, K}+L_{P, A}} .
$$

From (11),

$$
\sigma=\frac{\sigma_{K} L_{P, K}+\sigma_{A} L_{P, A}}{L_{P, K}+L_{P, A}} .
$$

From (12) and (13),

$$
\sigma=\frac{L_{P, K} \sigma_{K}^{2}+L_{P, A} \sigma_{A}^{2}}{L_{P, K} \sigma_{K}+L_{P, A} \sigma_{A}}
$$

when $\sigma_{K}=0, \sigma=\sigma_{A}$

when $\sigma_{A}=0, \sigma=\sigma_{K}$

when $\sigma_{K}=\sigma_{A}=1, \sigma=1$.

2.3. Reflection Coefficient. Equations (8)-(11) show that $\sigma_{K}$ and $\sigma_{A}$ appear in $\mu$ and $\rho$, and disappear in $\lambda$ and $\phi$. These events and (5) and (6) suggest that $\sigma_{K}$ and $\sigma_{A}$ do not exert an influence on electric current-driven mass transport, that is, migration and electro-osmosis. Reflection coefficient is a parameter indicating the permselectivity between solutes and solvent passing through the membrane. It is essentially the concept developed in pressure-driven dialysis. This phenomenon is conceivable in electrodialysis, but the concept developed in pressure dialysis is not directly applicable to the phenomenon in electrodialysis. In order to understand the behavior of the reflection coefficient in an electrodialysis process, it is necessary to establish a concept of zero current density. In other words, it is reasonable to image the electric current interruption (switch off) for a moment in the electrodialysis process operating under a constant electric current, and assume the disappearance of the migration and electro-osmosis in this moment. Here, we assume further that solute diffusion and hydraulic osmosis remain as they are just after the electric current interruption [10].

In order to discuss the behavior of the reflection coefficient in an electrodialysis process, we express the volume flow $J_{V}$ and exchange flow $J_{D}$ in an ion-exchange membrane pair by the following equations introduced by Schloegel [17]:

$$
\begin{aligned}
J_{V}= & \left(L_{P, K}+L_{P, A}\right) \Delta P \\
& +\left(L_{P D, K}+L_{P D, A}\right) R T \Delta C=\left(\frac{J_{S}}{C_{S}^{*}}\right)+\left(\frac{J_{W}}{C_{W}^{*}}\right), \\
J_{D}= & \left(L_{D P, K}+L_{D P, A}\right) \Delta P \\
& +\left(L_{D, K}+L_{D, A}\right) R T \Delta C=\left(\frac{J_{S}}{C_{S}^{*}}\right)-\left(\frac{J_{W}}{C_{W}^{*}}\right),
\end{aligned}
$$

$\Delta P$ and $\Delta C$ are pressure difference and concentration difference across the membrane, respectively. $L_{P}$ is the hydraulic conductivity and $L_{D}$ is the exchange flow parameter. $L_{P D}$ is the osmotic volume flow coefficient and $L_{D P}$ is the ultrafiltration coefficient. $J_{W}$ is the flux of water molecules. $C_{S}^{*}$ and $C_{W}^{*}$ are respectively, logarithmic mean concentration (3) of solutes and water (solvent) between a desalting cell and a concentrating cell. It should be noticed that (15) and (16) are originally defined in the pressure-driven transport (pressure dialysis) of neutral species with no electric current. Equation (15) presents the sum of the solute flux $J_{S}$ and solvent flux $J_{W}$, while (16) shows the difference between $J_{S}$ and $J_{W}$. It should be added that (6) expresses the solution flux $J_{V}$ and not expresses the solvent flux $J_{W}$.

In a pressure-driven process, putting $\Delta C=0$ in (15) and (16) introduces the following equation applicable to pressure dialysis:

$$
\begin{gathered}
\left(J_{V}\right)_{\Delta C=0}=\left(L_{P, K}+L_{P, A}\right) \Delta P, \\
\left(J_{D}\right)_{\Delta C=0}=\left(L_{D P, K}+L_{D P, A}\right) \Delta P,
\end{gathered}
$$

$\sigma_{K}$ and $\sigma_{A}$ included in (4) are defined by Staverman [18] and Kedem-Katchalsky [19] as follows:

$$
\begin{aligned}
& \sigma_{K}=-\left(\frac{J_{D, K}}{J_{V, K}}\right)_{\Delta C=0}=-\left(\frac{L_{D P, K}}{L_{P, K}}\right), \\
& \sigma_{A}=-\left(\frac{J_{D, A}}{J_{V, A}}\right)_{\Delta C=0}=-\left(\frac{L_{D P, A}}{L_{P, A}}\right) .
\end{aligned}
$$

We define the overall reflection coefficient $\sigma$ (14) using (18) and (19):

$$
\sigma=-\left(\frac{J_{D}}{J_{V}}\right)_{\Delta C=0}=-\frac{L_{D P, K}+L_{D P, A}}{L_{P, K}+L_{P, A}} .
$$


$\sigma$ given in (20) is the reflection coefficient defined in the pressure-driven dialysis. Here, we term $\sigma$ "overall pressure reflection coefficient," because it is the membrane pair characteristic and reflects pressure difference $\Delta P$-driven phenomenon.

$\sigma$ given in (18)-(20) defines the permselectivity between water (solvent) and solutes and it is originally established in pressure-dialysis. For understanding the permselectivity between water and solutes (ions) in electrodialysis, $\sigma$ is fundamentally inapplicable. The permselectivity between water and ions in electrodialysis must be explained on the basis of $\sigma^{*}$ (overall concentration reflection coefficient) described below.

In the electrodialysis process, $\Delta P$ is relatively low and negligible, and just after an electric current interruption (switch off), $\Delta C$ remains as it is. Putting $\Delta P=0$ in (15) and (16) introduces the following equations applicable to electrodialysis:

$$
\begin{gathered}
\left(J_{V}\right)_{\Delta P=0}=\left(L_{P D, K}+L_{P D, A}\right) R T \Delta C \\
\left(J_{D}\right)_{\Delta P=0}=\left(L_{D, K}+L_{D, A}\right) R T \Delta C .
\end{gathered}
$$

We define here another reflection coefficient $\sigma^{*}$ introduced from (21) and generated just after an electric current interruption as follows:

$$
\sigma^{*}=-\left(\frac{J_{D}}{J_{V}}\right)_{\Delta P=0}=-\frac{L_{D, K}+L_{D, A}}{L_{P D, K}+L_{P D, A}} .
$$

$\sigma^{*}(22)$ is the reflection coefficient defined in electrodialysis, and it is termed "the overall concentration reflection coefficient" because it reflects a concentration difference $\Delta C$ driven phenomenon.

Koter [20] suggests that the Onsager reciprocity [5, $6]$ is not satisfied and the relationship between $L_{P D}$ and $L_{D P}$ depends on the concentration difference across the membrane. One example for Nafion 417 in $\mathrm{NaCl} / \mathrm{H}_{2} \mathrm{O}$ at $C^{\prime \prime} / C^{\prime}=2$ is $L_{D P} / L_{P D}=0.40$. Thus, the reciprocal equation is presented as follows:

$$
L_{D P, K}+L_{D P, A}=k\left(L_{P D, K}+L_{P D, A}\right) \quad k \neq 1,
$$

in which, $k$ is defined as the Onsager reciprocity coefficient. From (20), (22), and (23):

$$
\sigma \sigma^{*}=k \frac{L_{D, K}+L_{D, A}}{L_{P, K}+L_{P, A}} .
$$

Cancelling, $J_{W} / C_{W}^{*}$ in (15) and (16):

$$
J_{D}=2 \frac{J_{S}}{C_{S}^{*}}-J_{V} .
$$

From (22) and (25),

$$
\sigma^{*}=1-2\left(\frac{1}{C_{S}^{*}}\right)\left(\frac{J_{S}}{J_{V}}\right)_{\Delta P=0} .
$$

$\sigma^{*}$ presented in (26) gives the permselectivity between ions and water molecules just after an electric current interruption. $J_{S}$ and $J_{V}$ are expressed as the following equations just after an electric current interruption by putting $i=0$ in (5) and (6):

$$
\begin{gathered}
J_{S}=-\mu\left(C^{\prime \prime}-C^{\prime}\right), \\
J_{V}=\rho\left(C^{\prime \prime}-C^{\prime}\right) .
\end{gathered}
$$

Substituting (27) into (26):

$$
\sigma^{*}=1+2\left(\frac{\mu}{\rho}\right)\left(\frac{1}{C_{S}^{*}}\right) .
$$

2.4. Membrane Characteristics. Yamauchi and Yasuko Tanaka [21] measured $\sigma_{K}, L_{P, K}$, and $\omega_{K}$ of a cation-exchange membrane (Neosepta CL-25T, Tokuyama Soda Co. Ltd.) by means of pressure-driven dialysis of a $\mathrm{KCl}$ solution and found $\sigma_{K}$ to be unity. This phenomenon means that $\mathrm{K}^{+}$ions do not pass through the cation-exchange membrane due to the Donnan exclusion of co-ions $\left(\mathrm{Cl}^{-}\right.$ions $) . \sigma_{K}$ and $\sigma_{A}$ included in (9), (11) and (14) are equivalent to $\sigma_{K}$ measured in the above experiment. So, (8)-(11) are simplified as follows by substituting $\sigma_{K}=\sigma_{A}=1$ in (9), (11), and (14):

$$
\begin{gathered}
t_{K}+t_{A}=\lambda F+1, \\
\omega_{K}+\omega_{A}=\frac{\mu}{R T}, \\
\beta_{K}+\beta_{A}=\phi, \\
L_{P, K}+L_{P, A}=\frac{\rho}{R T} .
\end{gathered}
$$

Putting $\sigma=1$ in (20),

$$
L_{D P, K}+L_{D P, A}=L_{P, K}+L_{P, A} .
$$

From (24) and (32),

$$
k\left(K_{D, K}+L_{D, A}\right)=\frac{\rho \sigma^{*}}{R T}=\left(L_{P, K}+L_{P, A}\right) \sigma^{*} .
$$

\section{Experimental}

3.1. Electrodialysis 1. The following commercially available ion-exchange membranes were integrated into an electrodialyzer ED and formed an electrodialysis system [22] as illustrated in Figure 2.

Aciplex K172/A172, Asahi Chemical Co.

Selemion CMV/ASR, Asahi Glass Co.

Neosepta CIMS/ACS3. Tokuyama Inco.

The specifications of the membranes are listed in Table 1. The effective membrane area was maintained to 1.72 $\mathrm{dm}^{2}(18 \mathrm{~cm}$ length, $10 \mathrm{~cm}$ width). The flow-pass thickness in a desalting and a concentrating cell was $0.075 \mathrm{~cm}$. Number of cell pairs was 9. Seawater was supplied into the diluate tank DT, then it was supplied to desalting cells De at a linear velocity of $5 \mathrm{~cm} / \mathrm{s}$ keeping temperature to $25,35,50$, or $60^{\circ} \mathrm{C}$. Passing a constant electric current through the Ti/Pt-anode 
TABLE 1: Specifications of ion-exchange membranes.

\begin{tabular}{|c|c|c|c|c|c|c|c|}
\hline & & $\begin{array}{c}\text { Thickness } \\
\text { mm }\end{array}$ & $\begin{array}{l}\text { Electric } \\
\text { resistance } \\
\Omega \mathrm{cm}^{2}\end{array}$ & Transpor number & $\begin{array}{c}\text { Exchange } \\
\text { capacity } \\
\text { meq/dry memb. }\end{array}$ & $\begin{array}{c}\text { Water } \\
\text { content \% }\end{array}$ & $\begin{array}{c}\text { Intensity } \\
\mathrm{kg} / \mathrm{cm}^{2}\end{array}$ \\
\hline \multirow{4}{*}{ Aciplex } & K172 & $0.11-0.13$ & $1.9-2.2$ & $>0.99$ & $1.5-1.6$ & $20-30$ & $2.6-3.3$ \\
\hline & $\mathrm{A} 172$ & $0.11-0.15$ & $1.7-2.1$ & $>0.99$ & 1.8-1.9 & $24-25$ & $2.2-3.0$ \\
\hline & $\mathrm{CK} 2$ & 0.23 & 3.3 & 0.91 & & & \\
\hline & CA3 & $0.09-0.12$ & $1.5-2.0$ & & & & $1.3-2.0$ \\
\hline \multirow{4}{*}{ Selemion } & CMR & 0.11 & 2.36 & 0.94 & 3.7 & 34 & 2.0 \\
\hline & ASR & 0.11 & 1.80 & 0.96 & 3.5 & 33 & 2.0 \\
\hline & CMV2 & $0.11-0.15$ & $2.0-3.5$ & $>0.91$ & $1.5-1.8$ & $18-20$ & $3-5$ \\
\hline & AST & $0.11-0.13$ & $1.5-2.5$ & $>0.95$ & & & $1.5-2.5$ \\
\hline \multirow{4}{*}{ Neosepta } & CIMS & $0.14-0.17$ & $1.5-1.6$ & $>0.98$ & $2.2-2.5$ & $30-35$ & $3.1-4.1$ \\
\hline & ACS3 & $0.09-0.12$ & $1.5-2.0$ & $>0.98$ & $2.0-2.4$ & $20-30$ & $1.3-2.0$ \\
\hline & CL25T & $0.15-0.17$ & $2.2-3.0$ & $>0.98$ & $1.5-1.8$ & $25-35$ & 3-5 \\
\hline & AVS4T & $0.15-0.17$ & $3.7-4.7$ & $>0.98$ & $1.5-2.0$ & $25-30$ & $4-6$ \\
\hline
\end{tabular}

and stainless (SUS 304) cathode, concentrate was extracted from concentrating cells. Confirming the salt concentration of the concentrate to be stable, diluate and concentrate were sampled. Electrodialysis was repeated changing current density incrementally.

In Figure 2, partition cells were incorporated between the desalting cells and electrode cells and seawater was supplied to the partition cells for preventing the influence of electrode reactions to the performance of electrodialysis. Seawater was also supplied to the electrode cells. The electrode reactions are as follows:

$$
\begin{array}{cl}
\text { Anode: } & 2 \mathrm{Cl}^{-} \longrightarrow \mathrm{Cl}_{2}+2 \mathrm{e}^{-} \\
\text {Cathode: } & 2 \mathrm{H}_{2} \mathrm{O} \longrightarrow 2 \mathrm{H}^{+}+2 \mathrm{OH}^{-} \\
& 2 \mathrm{H}^{+}+2 \mathrm{e}^{-} \longrightarrow \mathrm{H}_{2} \\
& \mathrm{Mg}^{2+}+2 \mathrm{OH}^{-} \longrightarrow \mathrm{Mg}(\mathrm{OH})_{2}
\end{array}
$$

An $\mathrm{HCl}$ solution was supplied to the cathode cell to dissolve $\mathrm{Mg}(\mathrm{OH})_{2}$.

3.2. Electrodialysis 2. The following commercially available membranes were integrated into an electrodialyzer [10] similar to the unit in Figure 2: Aciplex CK2/CA3, Selemion CMV2/AST, Neosepta CL25T/AVS4T.

The specifications of the membranes are listed in Table 1. The effective membrane area was $5 \mathrm{dm}^{2}(25 \mathrm{~cm}$ length, $20 \mathrm{~cm}$ width). The flow-pass thickness in a desalting cell and concentrating cell was $0.12 \mathrm{~cm}$. Number of cell pairs was 10 . Diluted seawater $\left(0.294 \mathrm{eq} / \mathrm{dm}^{3}\right)$, seawater $\left(0.577 \mathrm{eq} / \mathrm{dm}^{3}\right)$, and concentrated seawater $\left(1.131\right.$ and $\left.1.920 \mathrm{eq} / \mathrm{dm}^{3}\right)$ were supplied into the diluate tank DT, then it was supplied to desalting cells De at a linear velocity of $5 \mathrm{~cm} / \mathrm{s}$ keeping temperature to $29^{\circ} \mathrm{C}$. Passing a constant electric current through graphite-stainless electrodes, concentrate was extracted from concentrating cells. Diluate and concentrate were sampled and electrodialysis was repeated changing current density step by step as described in the electrodialysis 1 .
3.3. Chemical Analysis. Concentration (eq/dm ${ }^{3}$ ) of $\mathrm{K}^{+}$, $\mathrm{Mg}^{2+}, \mathrm{Ca}^{2+}, \mathrm{Cl}^{-}$, and $\mathrm{SO}_{4}^{2-}$ ions in diluate and concentrate were analyzed. In seawater electrodialysis, total salt concentration $C$ is given as $C=C_{\mathrm{Na}}+C_{\mathrm{K}}+C_{\mathrm{Mg}}+C_{\mathrm{Ca}}=C_{\mathrm{Cl}}+C_{\mathrm{SO}_{4}}$. So, sodium ion concentration is given by $C_{\mathrm{Na}}=C_{\mathrm{Cl}}+C_{\mathrm{SO}_{4}}-$ $C_{\mathrm{K}}-C_{\mathrm{Ca}}-C_{\mathrm{Mg}}$.

\section{Results and Discussion}

4.1. Overall Mass Transport Equation and Overall Membrane Pair Characteristics; $\lambda, \mu, \phi$ and $\rho . J_{S} / i$ and $J_{V} / i$ are plotted against $\Delta C / i$ and exemplified in Figures 3 and 4 . From these plots, overall transport number $\lambda$, overall solute permeability $\mu$, overall electro-osmotic permeability $\phi$, and overall hydraulic permeability $\rho$ are calculated as shown in the figures. The gradient of $J_{S} / i$ versus $\Delta C / i$ is usually negative, so $\mu$ is positive (Figure 3 ). However, the gradient occasionally gives positive, so $\mu$ becomes negative (Figure 4). $\mu$ values of the commercially available membranes are generally very small due to the Donnan exclusion of the membranes against co-ions and their dense structure. Using the overall mass transport equation, $\mu$ can be detected from the above gradients. Overall membrane pair characteristics observed in this investigation are listed in Table 2. $\mu$ values of the Neosepta CIMS/ACS3 membranes (Electrodialysis 1) and the Selemion CMV2/AST membranes (Electrodialysis 2) are found to be negative.

4.2. Membrane Characteristics $t, \omega, \beta$, and $L_{P}$. Substituting $\lambda, \mu, \phi$, and $\rho$ into (29)-(32), membrane characteristics (phenomenological coefficients) such as transport number $t_{K}+t_{A}$, solute permeability $\omega_{K}+\omega_{A}$, electro-osmotic permeability $\beta_{K}+\beta_{A}$, and hydraulic conductivity $L_{P, K}+L_{P, A}$ are calculated. $L_{D P, K}+L_{D P, A}$ is equivalent to $L_{P, K}+L_{P, A}$ as defined in (33).

Figures 5-8 show the relationship between temperature $T$ and the membrane characteristics obtained in Section 2.1 Electrodialysis 1 . It is seen that $L_{P, K}+L_{P, A}$ increases 
TABLE 2: Overall membrane pair characteristics.

(a) Electrodialysis 1.

\begin{tabular}{|c|c|c|c|c|c|}
\hline $\begin{array}{l}\text { Ion-exchange } \\
\text { membrane }\end{array}$ & Temp. ${ }^{\circ} \mathrm{C}$ & $\lambda \times 10^{6} \mathrm{eq} / C$ & $\mu \times 10^{6} \mathrm{~cm} / \mathrm{s}$ & $\phi \times 10^{3} \mathrm{~cm} / C$ & $\rho \times 10^{2} \mathrm{~cm}^{4} /$ eq s \\
\hline \multirow{4}{*}{$\begin{array}{l}\text { Aciplex } \\
\text { K172/A172 }\end{array}$} & 25 & 9.724 & 1.434 & 1.403 & 1.218 \\
\hline & 35 & 9.736 & 1.289 & 1.370 & 1.626 \\
\hline & 50 & 9.972 & 4.515 & 1.542 & 1.996 \\
\hline & 60 & 9.692 & 2.123 & 1.405 & 2.765 \\
\hline \multirow{4}{*}{$\begin{array}{l}\text { Selemion } \\
\text { CMR/ASR }\end{array}$} & 25 & 9.389 & 1.482 & 1.409 & 1.116 \\
\hline & 35 & 9.422 & 2.421 & 1.501 & 1.377 \\
\hline & 50 & 9.475 & 3.614 & 1.563 & 1.937 \\
\hline & 60 & 9.583 & 5.103 & 1.621 & 2.380 \\
\hline \multirow{4}{*}{$\begin{array}{l}\text { Neosepta } \\
\text { CIMS/ACS3 }\end{array}$} & 25 & 9.349 & -1.055 & 1.004 & 1.254 \\
\hline & 35 & 9.373 & -1.679 & 1.067 & 1.538 \\
\hline & 50 & 9.459 & -1.239 & 1.067 & 1.835 \\
\hline & 60 & 9.547 & -0.561 & 1.405 & 2.059 \\
\hline
\end{tabular}

(b) Electrodialysis 2.

\begin{tabular}{|c|c|c|c|c|c|}
\hline $\begin{array}{l}\text { Ion-exchange } \\
\text { membrane }\end{array}$ & Conc. eq $/ \mathrm{dm}^{3}$ & $\lambda \times 10^{6} \mathrm{eq} / C$ & $\mu \times 10^{6} \mathrm{~cm} / \mathrm{s}$ & $\phi \times 10^{3} \mathrm{~cm}^{3} / C$ & $\rho \times 10^{2} \mathrm{~cm}^{4} /$ eq s \\
\hline \multirow{4}{*}{$\begin{array}{l}\text { Aciplex } \\
\text { CK2/CA3 }\end{array}$} & 0.294 & 9.482 & 6.028 & 1.699 & 1.226 \\
\hline & 0.576 & 9.407 & 8.570 & 1.619 & 1.234 \\
\hline & 1.131 & 8.970 & 6.977 & 1.514 & 1.280 \\
\hline & 1.920 & 8.953 & 9.690 & 1.367 & 1.387 \\
\hline \multirow{4}{*}{$\begin{array}{l}\text { Selemion } \\
\text { CMV2/AST }\end{array}$} & 0.294 & 9.055 & -1.443 & 1.294 & 5.945 \\
\hline & 0.577 & 9.371 & -0.731 & 1.316 & 5.787 \\
\hline & 1.131 & 9.389 & -0.424 & 1.296 & 5.893 \\
\hline & 1.921 & 9.139 & 0.850 & 1.193 & 6.371 \\
\hline \multirow{4}{*}{$\begin{array}{l}\text { Neosepta } \\
\text { CL25T/AVS4T }\end{array}$} & 0.294 & 9.584 & 1.458 & 1.513 & 6.354 \\
\hline & 0.577 & 9.633 & 3.208 & 1.394 & 6.788 \\
\hline & 1.132 & 9.228 & 0.908 & 1.304 & 7.566 \\
\hline & 1.920 & 9.269 & 3.575 & 1.254 & 7.691 \\
\hline
\end{tabular}

apparently with $T . \omega_{K}+\omega_{A}$ and $\beta_{K}+\beta_{A}$ increase slightly with T. $t_{K}+t_{A}$ is not influenced by T. $\omega_{K}+\omega_{A}$ for Neosepta CIMS/ACS3 membranes is negative (Figure 6) because $\mu<0$ (Table 2).

Figures 9-12 show the relationships between salt concentrations in desalting cells $C^{\prime}$ and membrane characteristics obtained in Section 2.2 Electrodialysis 2. $\beta_{K}+\beta_{A}$ decreases and $L_{P, K}+L_{P, A}$ increases to some extent with the increase of $C^{\prime} . t_{K}+t_{A}$ is not influenced by $C^{\prime} . \omega_{K}+\omega_{A}$ increases slightly with $C^{\prime}$ and it takes negative for Selemion CMV2/AST membranes (Figure 10) due to $\mu<0$ (Table 2).

4.3. Overall Concentration Reflection Coefficient $\sigma^{*}$. $\sigma^{*}$ is defined by the functions of current density because $\sigma^{*}$ is given by the function of logarithmic mean concentration $C_{S}^{*}$ (Equation (28)). However, the experimental results show that $\sigma^{*}$ is not influenced by current density. Thus, the observed $\sigma^{*}$ is averaged for each current density. Figures (13) and (14) show the $\sigma^{*}$ versus $T$ and $C^{\prime} . \sigma^{*}$ is generally larger than 1 , however, less than 1 for Neosepta CIMS/ACS3 membranes and for Selemion CMV2/AST membranes. The phenomena exhibited in Figures (13) and (14) are understandable as follows.

$\sigma^{*}$ defined in (26) gives the permselectivity between ions and water molecules just after an electric current interruption. Physical rationale of $\sigma^{*}$ is given by the following relationships realized in an electrodialysis system (Figure 15) incorporated with a cation- and an anionexchange membrane and cells I, II and III in which electrolyte solutions are filled:

$$
\begin{array}{ccc}
J_{\text {solute }}>0, & \sigma^{*}<1 & \mu<0, \\
J_{\text {solute }}=0, & \sigma^{*}=1 & \mu=0, \\
J_{\text {solute }}<0, & \sigma^{*}>1 & \mu>0 .
\end{array}
$$

In Figure 15, an electric current is passed through reversible electrodes and electrolyte concentration in cells I 


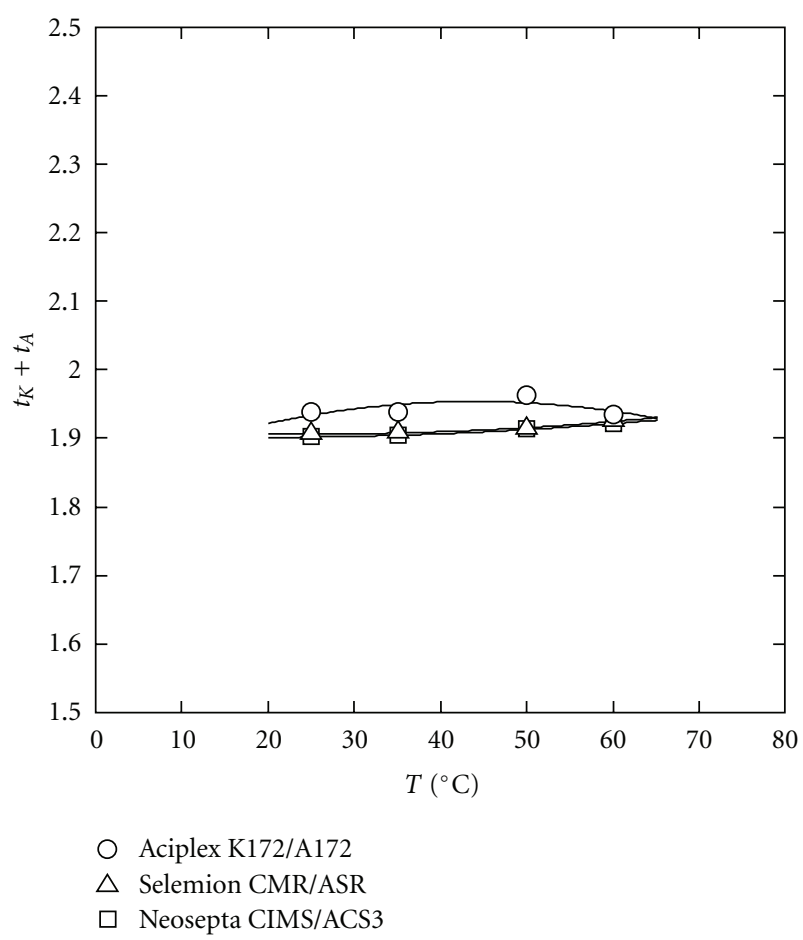

FIGURE 5: Relationship between temperature and transport number.

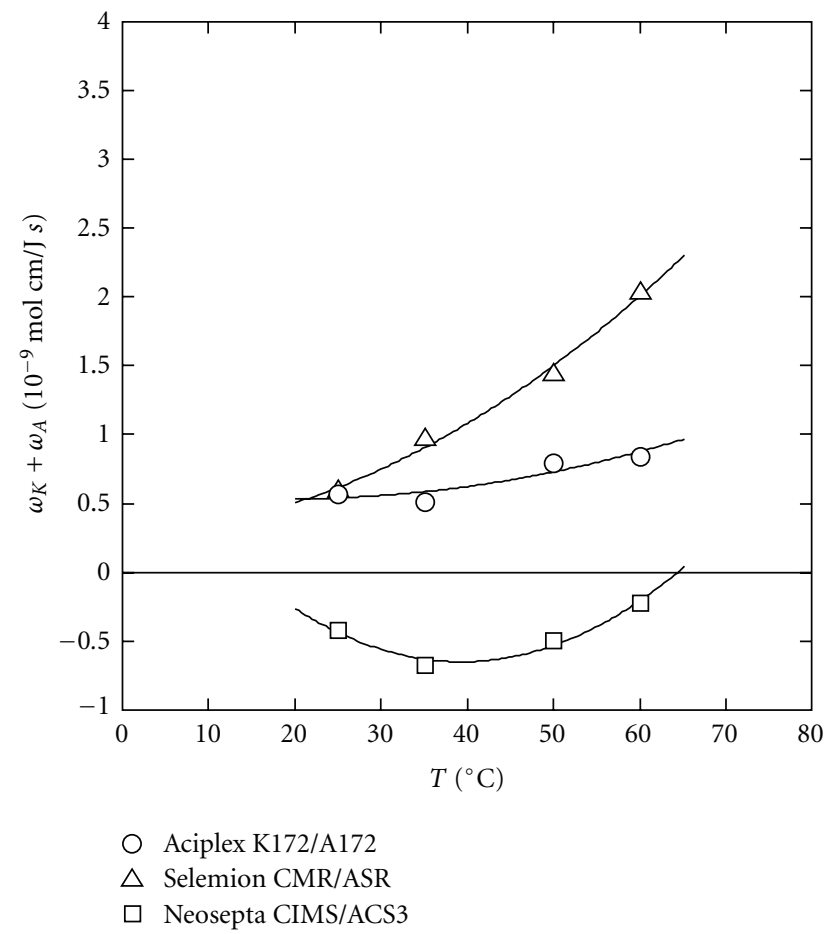

FIGURE 6: Relationship between temperature and solute permeability.

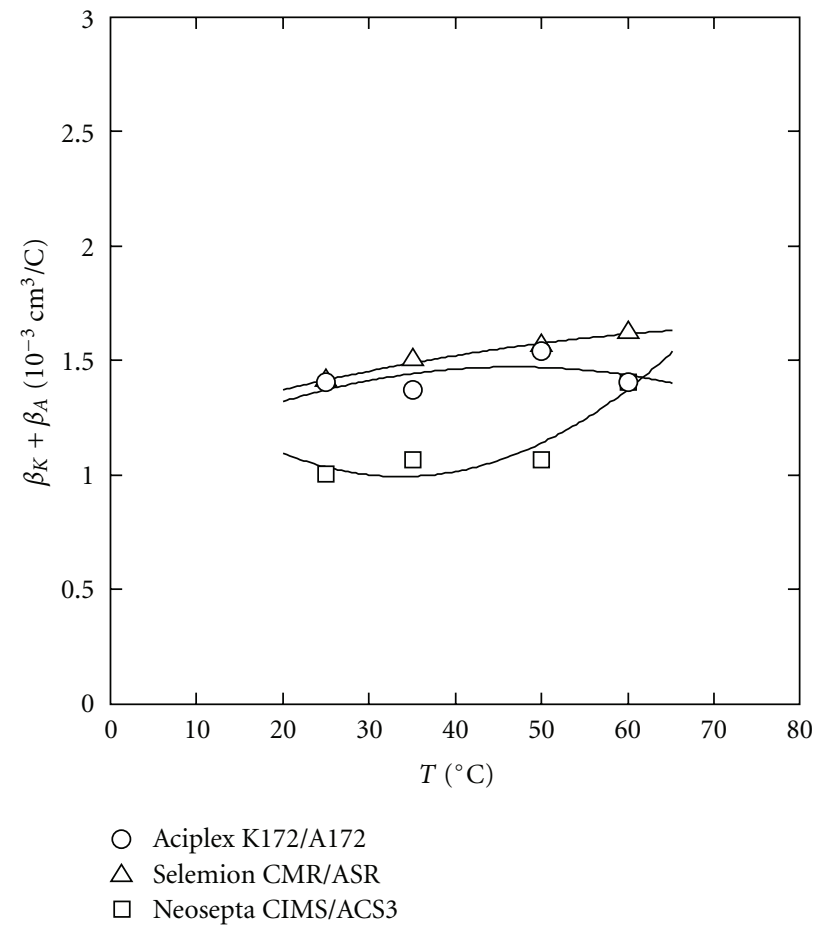

FIGURE 7: Relationship between temperature and electro-osmotic permeability.

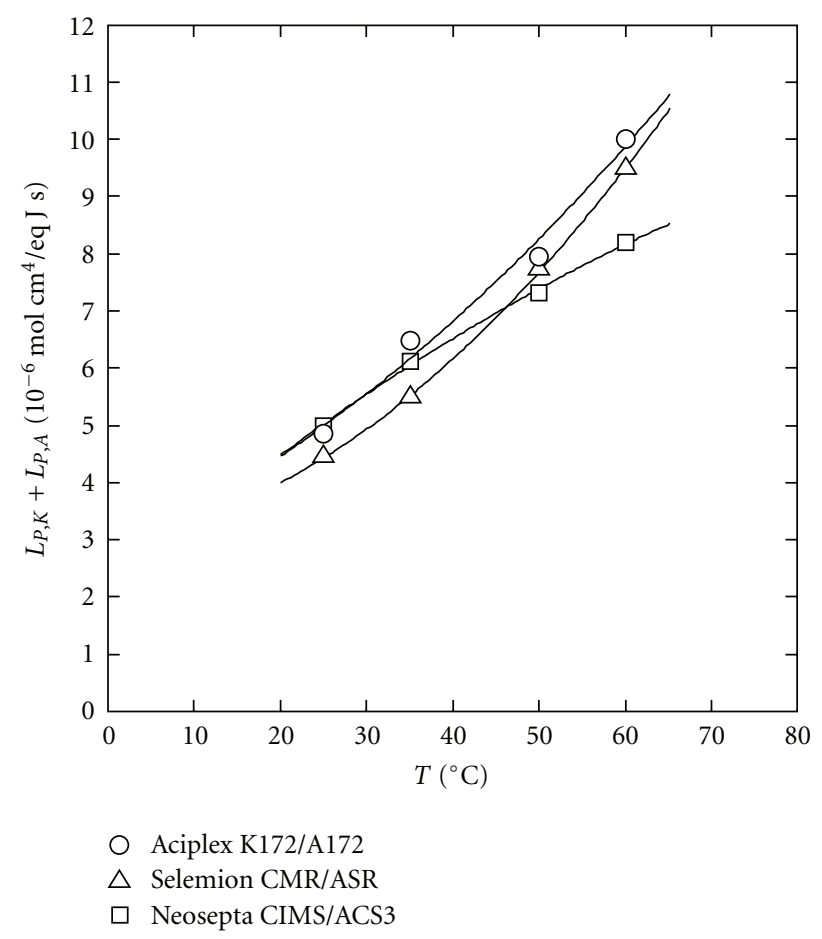

FIGURE 8: Relationship between temperature and hydraulic permeability. 


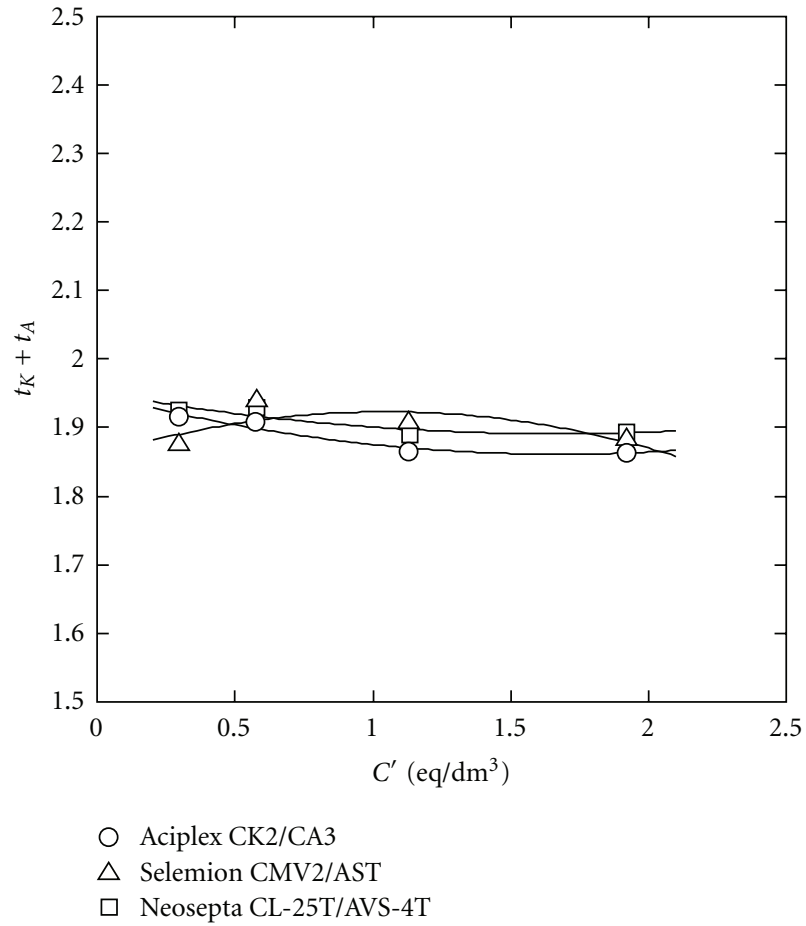

FIGURE 9: Relationship between salt concentration in a feeding solution and transport number.

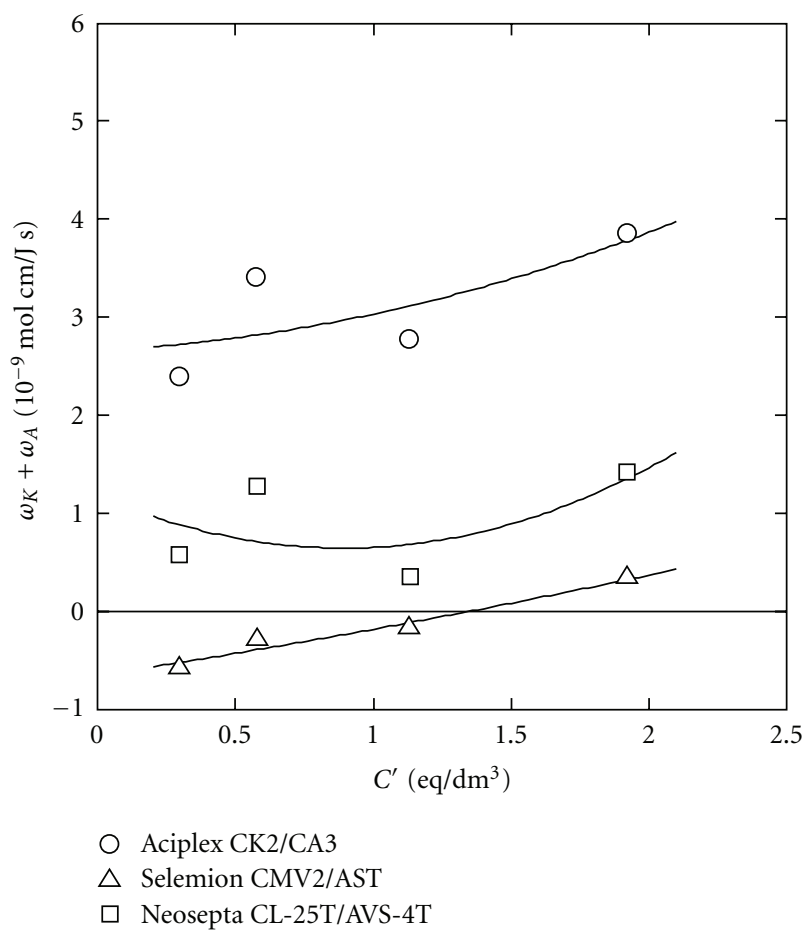

FIGURE 10: Relationship between salt concentration in a feeding solution and solute permeability.

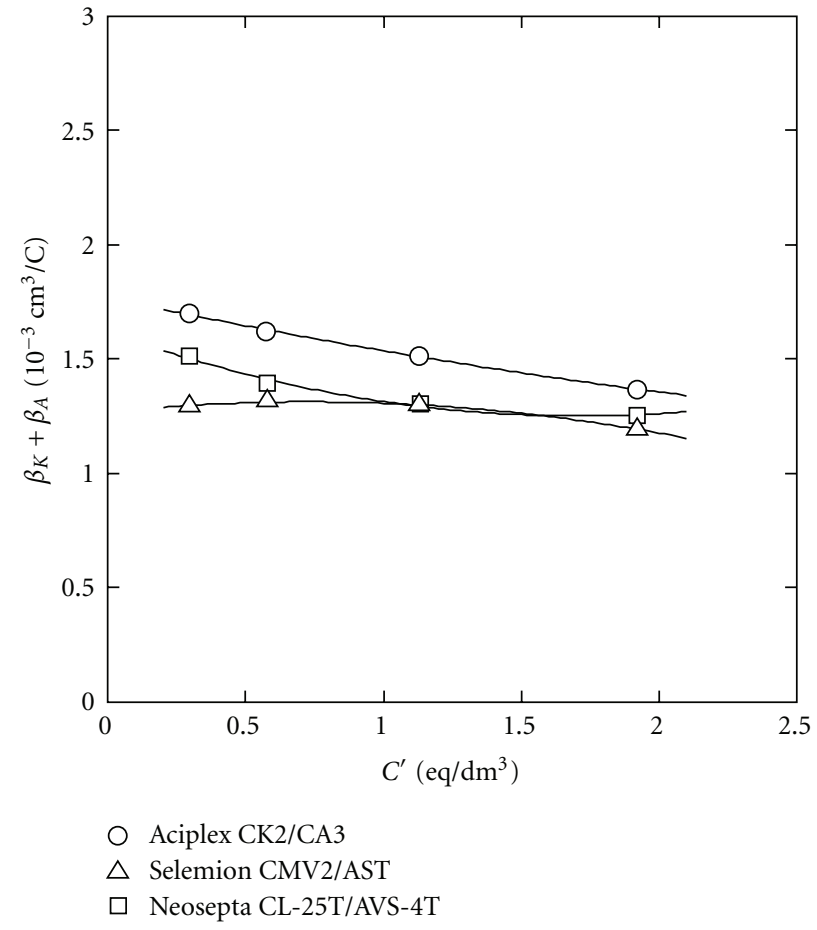

FIGURE 11: Relationship between salt concentration in a feeding solution and electro-osmotic permeability.

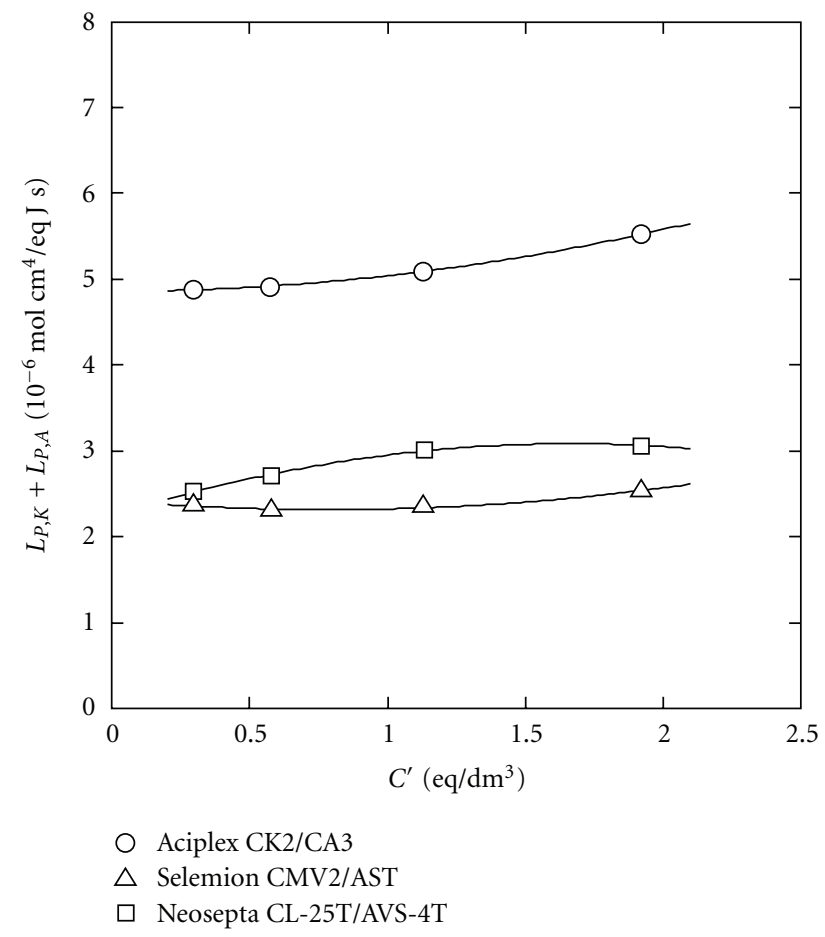

FIGURE 12: Relationship between salt concentration in a feeding solution and hydraulic conductivity. 


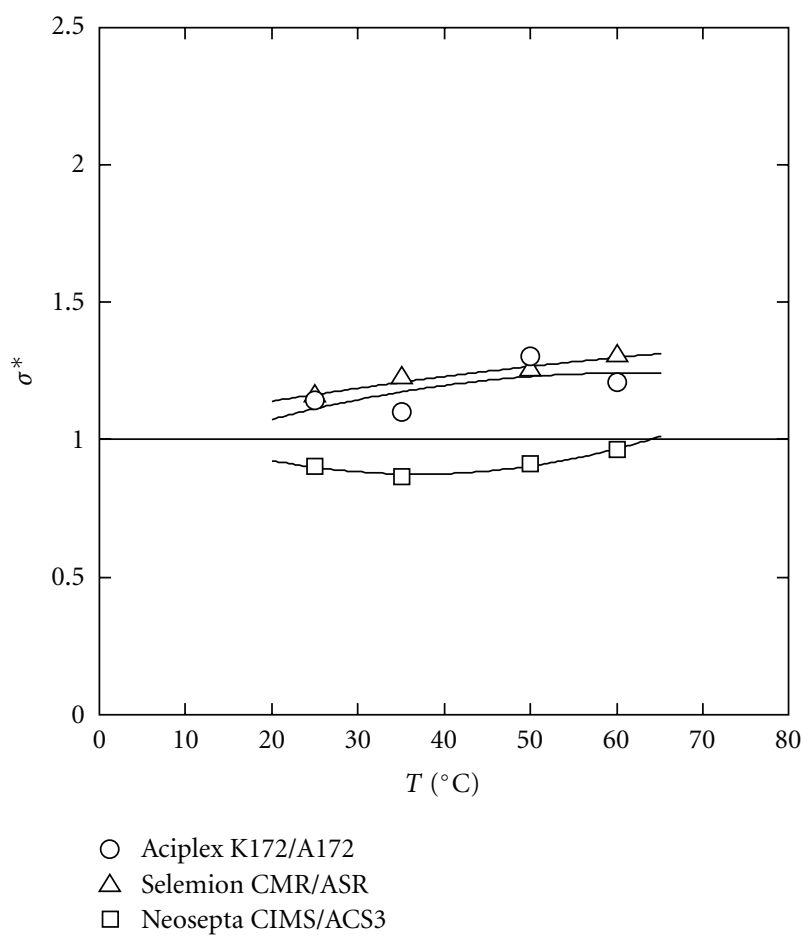

FIGURE 13: Relationship between temperature and overfull concentration reflection coefficient.

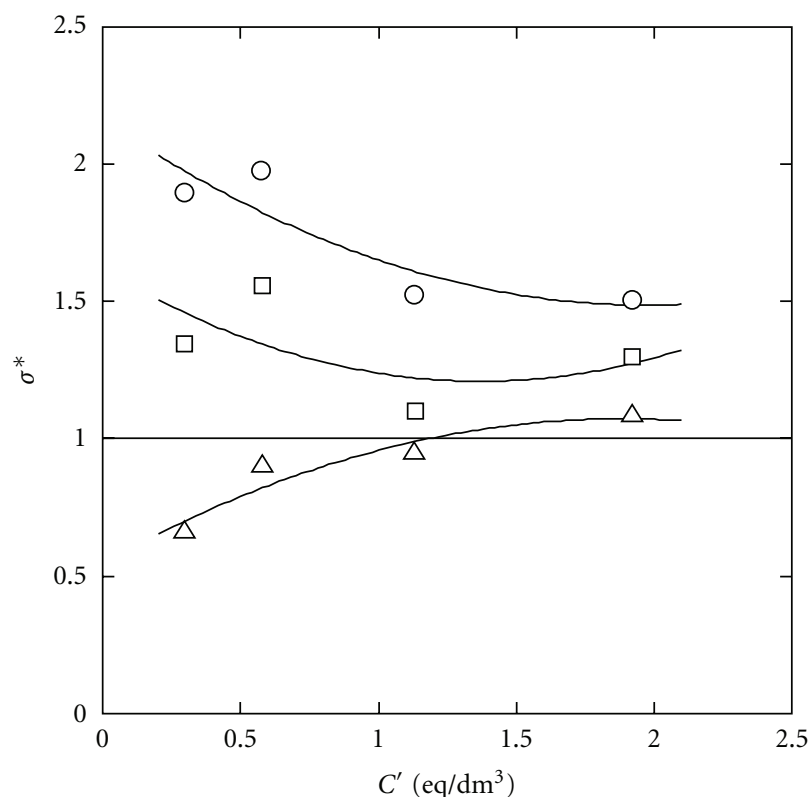

Aciplex CK2/CA3

$\triangle$ Selemion CMV2/AST

$\square$ Neosepta CL-25T/AVS-4T

FIGURE 14: Relationship between salt concentration in a feeding solution and overfull concentration reflection coefficient.

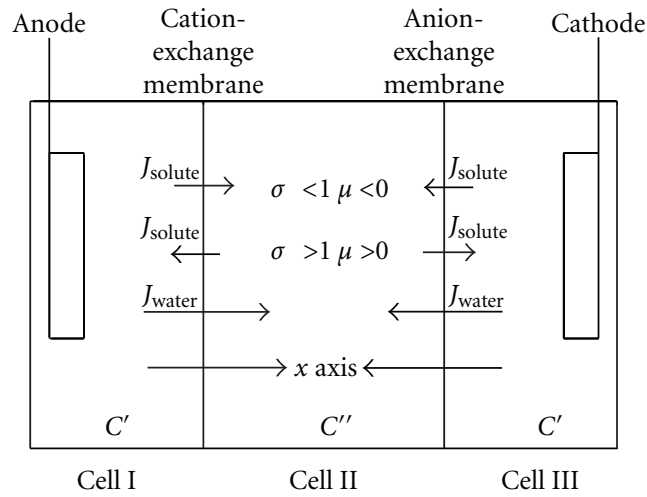

FIGURE 15: Electrodialysis system.

and III is assumed to be decreased to $C^{\prime}$ and that in cell II is increased to $C^{\prime \prime}\left(C^{\prime}<C^{\prime \prime}\right)$. The $x$ axis is drawn across each ion-exchange membrane as shown in the figure. Direction of water flux $J_{\text {water }}$ is positive $\left(J_{\text {water }} 0\right) ; J_{V}$ is positive $\left(J_{V}>0\right)$ in every situation.

Solute flux across the membrane is generally negative $\left(J_{\text {solute }}<0\right)$ and it moves from the concentrating cell (cell II) toward desalting cells (cells I and III) due to solute diffusion just after an electric current interruption. In this situation, the concentration reflection coefficient is larger than 1 (Equation (39), $\sigma^{*}>1$, Figures 13 and 14). This phenomenon is ordinary in electrodialysis, but extraordinary in pressure dialysis because the direction of the solute due to solute diffusion is against water flux due to hydraulic osmosis. In this case, the overall solute permeability becomes positive, that is, $\mu>0$ (Table 2) and $\omega_{K}+\omega_{A}>0$ (Figurs 6 and 10).

In Neosepta CIMS/ACS3 membranes and Selemion CMV2/AST membranes, solutes move from the desalting cells (cells I and III) toward concentrating cell (cell II) $\left(J_{\text {solute }}>0\right)$ just after an electric current interruption. In this situation, the concentration reflection coefficient is less than 1 (Equation (37), $\sigma^{*}<1$, Figures 13 and 14). This phenomenon is ordinary in pressure dialysis because the direction of the solute is the same to the water flux due to hydraulic osmosis. The overall solute permeability in this situation becomes negative $(\mu<0)$ (Table 2). The negative $\mu$ is indicative of coupled transport between water and solute, which is demonstrated also by negative $\omega_{K}+\omega_{A}$ (Figures 6 and 10). However, this phenomenon is extraordinary in electrodialysis because it means uphill transport of solutes against the concentration difference $\left(C^{\prime \prime}-C^{\prime}\right)$.

In repeating words, ions (solutes) transfer (diffuse) generally from concentrating cells toward desalting cells $(\mu>0$, $\left.\sigma^{*}>1, \omega_{K}+\omega_{A}>0\right)$. This direction of solute flux $\left(J_{\text {solute }}<0\right)$ is ordinary in electrodialysis but extraordinary in pressure dialysis because the direction of solute flux is against water flux $\left(J_{\text {water }}>0\right)$. In some cases, ions transfer from desalting cells toward concentrating cells $\left(\mu<0, \sigma^{*}<1, \omega_{K}+\omega_{A}<0\right)$. This direction of solute flux $\left(J_{\text {solute }}>0\right)$ is extra-ordinary in electrodialysis, but ordinary in pressure dialysis because the direction of solute flux is the same to water flux $\left(J_{\text {water }}>\right.$ 


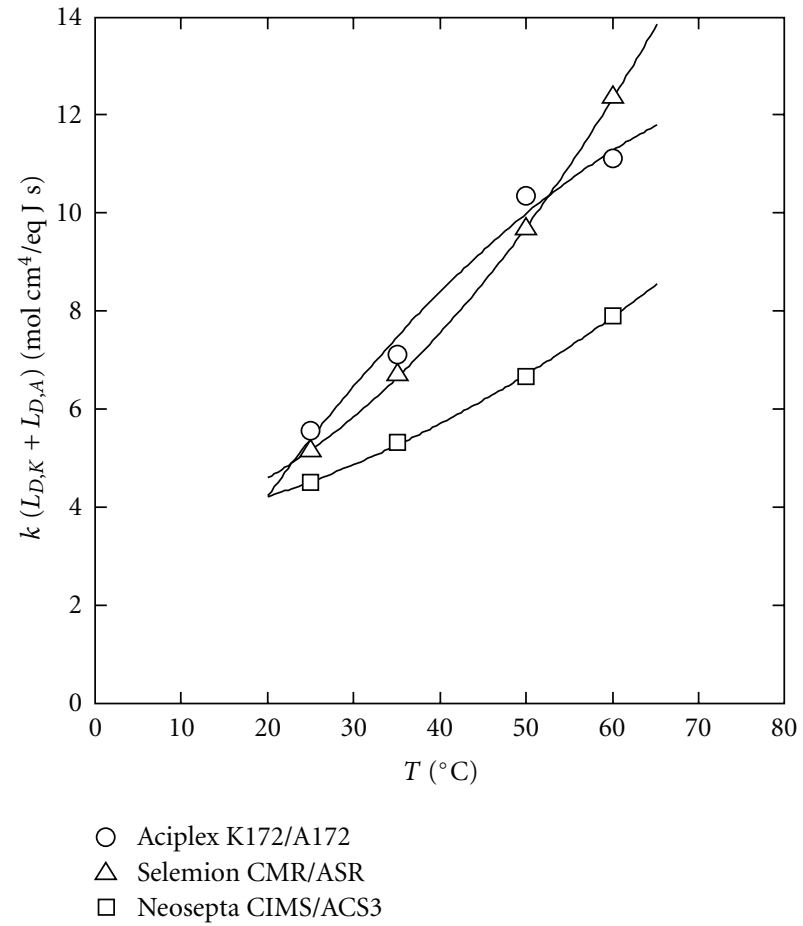

Figure 16: Relationship between temperature and exchange flow parameter.

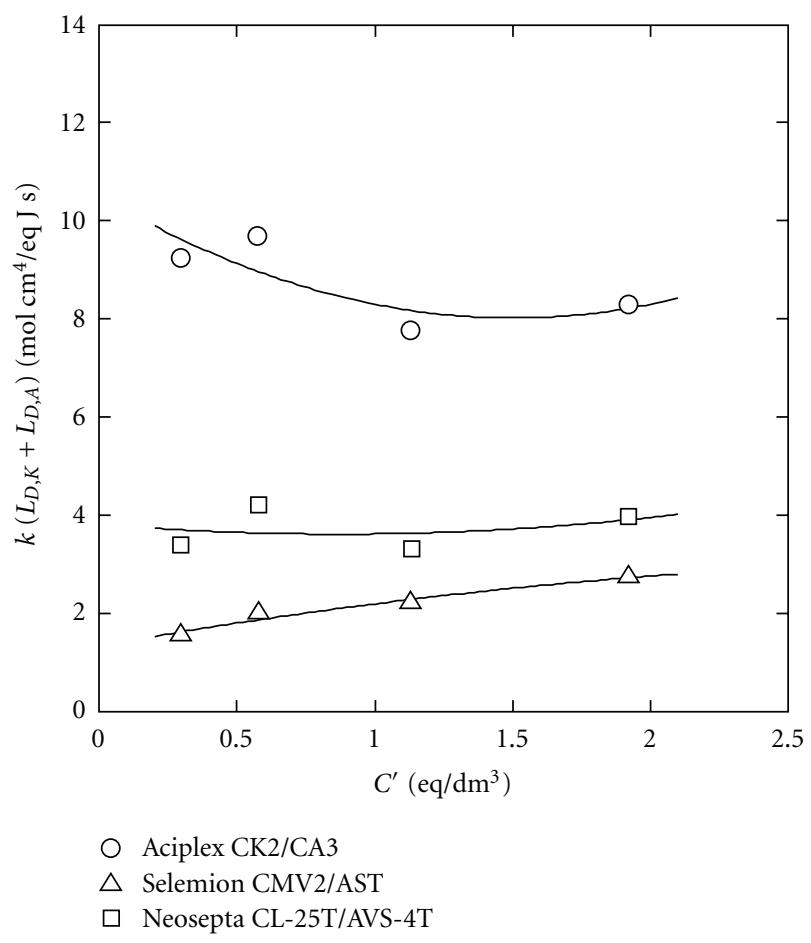

FIGURE 17: Relationship between salt concentration in a feeding solution and exchange flow parameter.
0 ), which indicates up-hill transport or coupled transport between water and solutes.

4.4. Exchange Flow Parameter $L_{D} \cdot k\left(L_{D, K}+L_{D, A}\right)$ is calculated from $\rho$ and $\sigma^{*}$ (Equation (34)). $\rho$ is the leading parameter and the other membrane characteristics are governed by $\rho$. [10]. $k\left(L_{D, K}+L_{D, A}\right)$ is increased with $T$ (Figure 16) and hardly influenced by $C^{\prime}$ (Figure 17). These phenomena are caused by that $\rho$ is increased with $T$ and hardly influenced by $C^{\prime}$.

\section{Conclusion}

Phenomenological coefficients such as transport number, solute permeability, electro-osmotic permeability, hydraulic permeability, and exchange flow parameter included in the phenomenological equations are evaluated by electrodialysis based on the overall mass transport equation. The overall reflection coefficient $\sigma$ is essentially the concept applied in pressure-driven dialysis. In order to understand the behavior of the overall reflection coefficient in an electrodialysis process, the concept of the overall concentration reflection coefficient $\sigma^{*}$ is applied. $\sigma^{*}$ presents the permselectivity between ions and water molecules across a membrane pair just after an electric current interruption in an electrodialysis process. $\sigma^{*}$ is generally larger than 1 and at the same time the overall solute permeability $\mu$ is positive in usual commercially available ion-exchange membranes. However, occasionally $\sigma^{*}$ becomes less than 1 and $\mu$ becomes negative, which indicates up-hill transport or coupled transport between water and solutes.

\section{Nomenclature}

C: Concentration (equiv. $\mathrm{cm}^{-3}$ )

$C^{*}$ : Mean concentration (equiv. $\mathrm{cm}^{-3}$ )

$F: \quad$ Faraday constant $\left(\mathrm{C}_{\text {equiv. }}{ }^{-1}\right)$

$i$ : Current density $\left(\mathrm{A} \mathrm{cm}^{-2}\right)$

I: $\quad$ Electric current (A)

$J: \quad$ Volume flow $\left(\mathrm{cm} \mathrm{s}^{-1}\right)$

$J_{D}:$ Exchange flow $\left(\mathrm{cm} \mathrm{s}^{-1}\right)$

$J_{S}: \quad$ Salt flux (equiv. $\mathrm{cm}^{-2} \mathrm{~s}^{-1}$ )

$J_{V}:$ Volume flux $\left(\mathrm{cm}^{3} \mathrm{~cm}^{-2} \mathrm{~s}^{-1}\right)$

$J_{W}$ : Flux of water molecules $\left(\mathrm{mol} \mathrm{cm} \mathrm{cm}^{-2} \mathrm{~s}^{-1}\right)$

$k$ : Onsager reciprocity coefficient

$L_{D}$ : Exchange flow parameter $\left(\mathrm{mol} \mathrm{cm}{ }^{4}\right.$ equiv. ${ }^{-1} \mathrm{~J}^{-1} \mathrm{~s}^{-1}$ )

$L_{D P}$ : Ultrafiltration coefficient ( $\mathrm{mol}$ $\mathrm{cm}^{4}$ equiv. ${ }^{-1} \mathrm{~J}^{-1} \mathrm{~s}^{-1}$ )

$L_{P}: \quad$ Hydraulic conductivity (mol $\mathrm{cm}^{4}$ equiv. ${ }^{-1} \mathrm{~J}^{-1} \mathrm{~s}^{-1}$ )

$L_{P D}$ : Osmotic volume flow coefficient (mol $\mathrm{cm}^{4}$ equiv. $\left.{ }^{-1} \mathrm{~J}^{-1} \mathrm{~s}^{-1}\right)$

$R: \quad$ Gas constant $\left(\mathrm{JK}^{-1} \mathrm{~mol}^{-1}\right)$

$t$ : Transport number

T: $\quad$ Temperature $\left({ }^{\circ} \mathrm{C}, \mathrm{K}\right)$. 
Greek symbols

$\beta: \quad$ Electro-osmotic permeability $\left(\mathrm{cm}^{3} \mathrm{C}^{-1}\right)$

$\Delta C$ : Concentration difference (equiv. $\mathrm{cm}^{-3}$ )

$\Delta P$ : Hydraulic pressure difference $\left(\right.$ dyn $\left.\mathrm{cm}^{-2}\right)$

$\Delta \psi$ : Potential difference (V)

$\Delta \mu$ : Chemical potential difference $\left(\mathrm{J} \mathrm{mol}^{-1}\right)$

$\lambda$ : Overall transport number (equiv. $\mathrm{C}^{-1}$ )

$\mu$ : Overall solute permeability $\left(\mathrm{cm} \mathrm{s}^{-1}\right)$

$\rho$ : Overall hydraulic permeability

${\text { ( } \mathrm{cm}^{4} \text { equiv. }}^{-1} \mathrm{~s}^{-1}$ )

$\sigma$ : Reflection coefficient, overall pressure reflection coefficient

$\sigma^{*}$ : Overall concentration reflection coefficient

$\phi$ : Overall electro-osmotic permeability $\left(\mathrm{cm}^{3} \mathrm{C}^{-1}\right)$

$\omega$ : Solute permeability $\left(\mathrm{mol} \mathrm{cm} \mathrm{J} \mathrm{J}^{-1} \mathrm{~s}^{-1}\right)$.

\section{Subscript}

A: Anion-exchange membrane

i: Component

$K$ : Cation-exchange membrane

S: Solute

$W$ : Water molecule (solvent).

Superscript

': Desalting cell

": Concentrating cell.

\section{Acknowledgment}

The authors are grateful to Mr. S. Nagatsuka and Mr. M. Akiyama, Odawara Salt Experimental Station, Japan Tobacco and Salt Public Corp. for their cooperation in the experimental work.

\section{References}

[1] I. Progogine, Introduction to Thermodynamics of Irreversible Processes, John Wiley, New York, NY, USA, USA, 2nd edition, 1961.

[2] P. Glansdorff and I. Prigogine, Thermodynamic Theory Structure, Stability and Fluctuations, Wiley-Interscience, London, UK, 1971.

[3] S. R. de Groot and P. Mazur, Nonequilibrium Thermodynamics, North-Holland, New York, NY, USA, 1962.

[4] D. D. Fitts, Nonequilibrium Thermodynamics, Mc-Graw Hill, New York, NY, USA, 1962.

[5] L. Onsager, "Reciprocal relations in irreversible processes. I.," Physical Review, vol. 37, no. 4, pp. 405-426, 1931.

[6] L. Onsager, "Reciprocal relations in irreversible processes. II," Physical Review, vol. 38, no. 12, pp. 2265-2279, 1931.

[7] H. B. G. Casimir, "On Onsager's principle of microscopic reversibility," Reviews of Modern Physics, vol. 17, no. 2-3, pp. 343-350, 1945.
[8] P. J. Dunlop, "A study of interacting flows in diffusion of the system raffinose- $\mathrm{KCl}-\mathrm{H}_{2}$ at $25^{\circ} \mathrm{C}$," Journal of Physical Chemistry, vol. 61, no. 7, pp. 994-1000, 1957.

[9] P. J. Dunlop and L. J. Gosting, "Use of diffusion and thermodynamic data to test the Onsager reciprocal relation for isothermal diffusion in the system $\mathrm{NaCl}-\mathrm{KCl}-\mathrm{H}_{2} \mathrm{O}$ at $25^{\circ} \mathrm{C}$," Journal of Physical Chemistry, vol. 63, no. 1, pp. 86-93, 1959.

[10] Y. Tanaka, "Irreversible thermodynamics and overall mass transport in ion-exchange membrane electrodialysis," Journal of Membrane Science, vol. 281, no. 1-2, pp. 517-531, 2006.

[11] Y. Tanaka, "A computer simulation of continuous ion exchange membrane electrodialysis for desalination of saline water," Desalination, vol. 249, no. 2, pp. 809-821, 2009.

[12] Y. Tanaka, "A computer simulation of batch ion exchange membrane electrodialysis for desalination of saline water," Desalination, vol. 249, no. 3, pp. 1039-1047, 2009.

[13] Y. Tanaka, "A computer simulation of feed and bleed ion exchange membrane electrodialysis for desalination of saline water," Desalination, vol. 254, no. 1-3, pp. 99-107, 2010.

[14] O. Kedem and A. Katchalsky, "Permeability of composite membranes Part 1. Electric current, volume flow and flow of solute through membranes," Transactions of the Faraday Society, vol. 59, pp. 1918-1930, 1963.

[15] C. R. House, Water Transport in Cells and Tissues, Edward Arnold, London, UK, 1974.

[16] S. G. Schultz, Basic Principles of Membrane Transport, Cambridge University Press, Cambridge, UK, 1980.

[17] R. Z. Schloegel, Fortschritte der physikalischen Chemie. Band 9, 1964.

[18] A. J. Staverman, "The theory of measurement of osmotic pressure," Recueil des Travaux Chimiques des Pays-Bas, vol. 70, no. 4, pp. 344-352, 1951.

[19] O. Kedem and A. Katchalsky, "Thermodynamic analysis of the permeability of biological membranes to non-electrolytes," Biochimica et Biophysica Acta, vol. 27, no. 2, pp. 229-246, 1958.

[20] S. Koter, "Transport of electrolytes across cation-exchange membranes. Test of Onsager reciprocity in zero-current processes," Journal of Membrane Science, vol. 78, no. 1-2, pp. 155-162, 1993.

[21] A. Yamauchi and Y. Tanaka, "Salt transport phenomena across charged membrane driven by pressure difference," in Effective Membrane Process-New Prospective, R. Paterson, Ed., pp. 179-185, BHR Group; Information Press, Oxford, UK, 1993.

[22] Y. Tanaka, "Ion exchange membrane electrodialysis of saline water desalination and its application to seawater concentration," Industrial \& Engineering Chemistry Research, vol. 50, no. 12, pp. 7494-7503, 2011. 

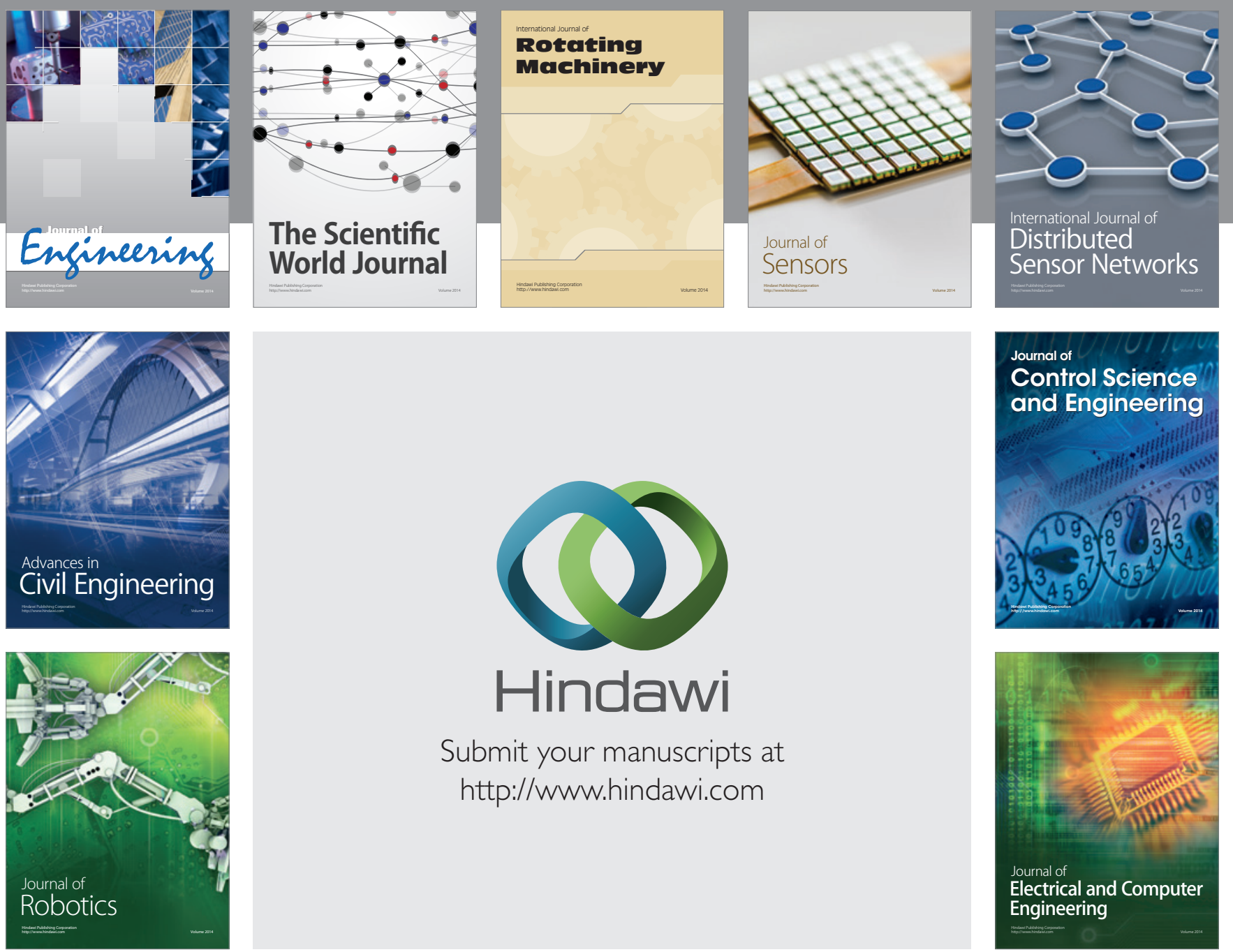

Submit your manuscripts at

http://www.hindawi.com
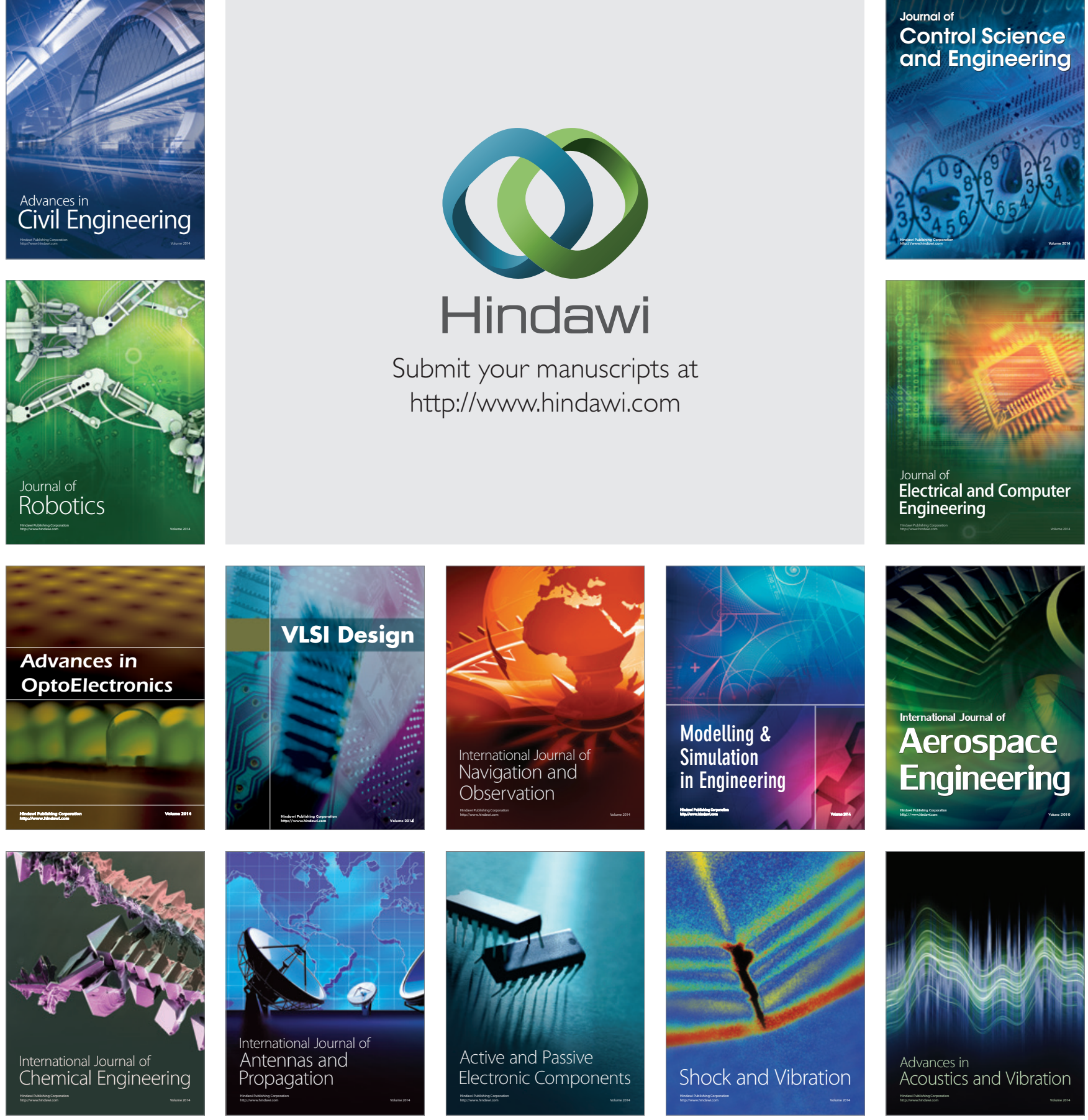